\title{
Study on Waste Heat Resource Utilization System for a Mine
}

\author{
Zhang Lu, Zhu Jian*, Tang Lingling \\ College of Civil and Hydraulic Engineering, Hefei University of Technology, Hefei, China
}

Email address:

1176859372@qq.com (Zhang Lu), zhujian@hfut.edu.cn (Zhu Jian)

${ }^{*}$ Corresponding author

\section{To cite this article:}

Zhang Lu, Zhu Jian, Tang Lingling. Study on Waste Heat Resource Utilization System for a Mine. International Journal of Industrial and Manufacturing Systems Engineering. Vol. 3, No. 2, 2018, pp. 11-16. doi: 10.11648/j.ijimse.20180302.11

Received: June 25, 2018; Accepted: August 3, 2018; Published: August 30, 2018

\begin{abstract}
There are a lot of low temperature heat energy in mine return air, and the temperature and humidity are basically constant. This part of heat energy has considerable use value. In this paper, a combination of heat pump technology and return heat recovery unit is proposed, and a small amount of electric energy is used to convert low level heat energy into high heat energy in the return air of the mine, thus replacing the traditional coal-fired boiler system, providing heat source for heating, wellhead antifreeze, and living hot water in the whole year, reducing the use of coal mine in mining area. Reducing the discharge of pollutants has realized the ecological concept of coal mining without coal in the real sense. The research project is located at $20 \mathrm{~km}$, west of Fengtai County, Anhui province. The administrative divisions belong to yuezhang Town, Fengtai county. This paper, based on the principle of the mine air source heat pump system, expounds the composition and characteristics of the system, and finally analyzes the economic and social benefits of the project. As the coal mine air source heat pump system uses the waste heat of the mine, the utilization cost of energy is far lower than that of other forms of energy supply. Therefore, the mine return air source heat pump system has good benefits in both social and economic sense. It is worth extensive research and research.
\end{abstract}

Keywords: Mine Return Air, Air Compressor Waste Heat, Recycle, Economic Analysis

\section{Introduction}

In China, the energy structure is mainly dependent on the combustion of minerals, especially the coal mineral combustion produces a large number of harmful gases such as $\mathrm{CO}_{2}$ and $\mathrm{SO}_{2}$, and the environmental problem can not be overlooked [1]. Coal mine industrial sites have heating needs such as bathing hot water and building heating, which are generally provided by coal (oil) fired boilers, and in the process of burning coal (fuel), a large amount of exhaust gas is emitted to the surrounding environment, resulting in environmental pollution [2-4]. There is a rich heat energy in the mine air return. According to incomplete statistics, the air return temperature of the mine is kept at $18 \sim 28$ degrees, the relative humidity is more than $90 \%$, which is almost unaffected by the external environment. It is a kind of stable high quality waste heat resource [5]. It is found that there is a lot of heat energy in the ventilation of the mine and the operation process of the fan. It is a great significance to change the traditional heat supply mode of coal mine and save energy and reduce emission of air pollutant by using the coal mine air source heat pump technology and the waste heat recovery technology of the fan [6]. In 2009, in view of the environmental problems such as low pressure and low temperature in the Northwest Plateau, Sheng and Xin [7, 8] proposed the idea of building the recovery system for the waste heat heat pipe of mine ventilation, and demonstrated the feasibility of this concept from two aspects of economy and technology. According to the characteristics of Zhangxiaolou Coal Mine, Guo adopted return air from the deep mine as the cooling energy for deep mine cooling system [9]. Taking Sanhejian coal mine as an example, Ting introduced the technology scheme of heat disaster governance by using surface water cold source [10].

The research project is located at $20 \mathrm{~km}$, west of Fengtai County, Anhui province. The administrative divisions belong to zhangyue Town, Fengtai county. The project will combine the actual situation of the mining area, applying the existing advanced energy saving technologies, carrying out the analysis and designing of waste heat recovery and utilization, adopting the new technology of recovery of the mine air return 
heat pump and the residual heat of the fan. It can provide the heat resource for the winter heating, the wellhead antifreeze and the living hot water in the factory area. Meanwhile, It also practices the concept of "low carbon operation ecological mine construction".

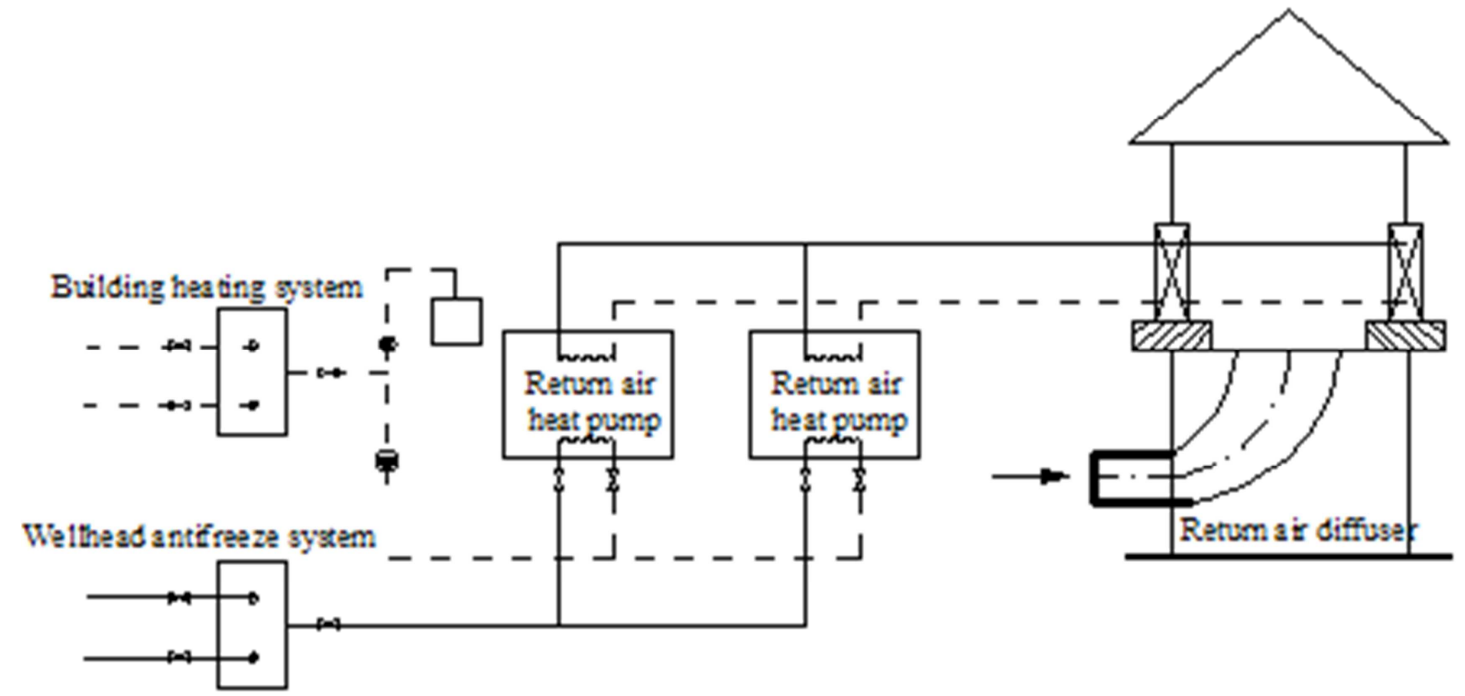

Figure 1. The system diagram of mine return air heat pump system.

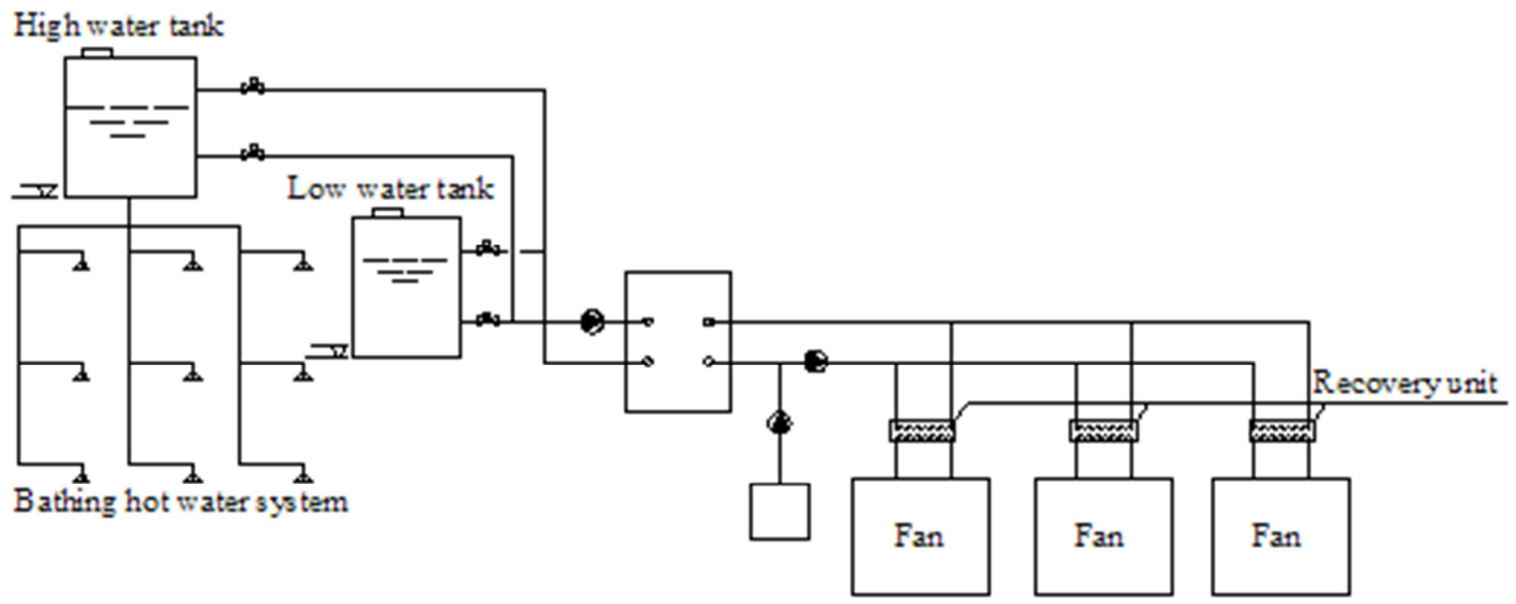

Figure 2. The principle of air compressor.

\section{Work Princil}

The coal mine air source heat pump system is composed of the mine air return heat exchanger and the diffusion tower (the two parties constitute the return air heat exchange device), the power plant, the pool, the sink and the accessories. The core device of the mine return air heat recovery system is the return air heat exchanger. The return air of the mine is pressed into the diffusion tower under the fan, so that the return air of the mine is converted into low-speed, uniform and stable air flow. The air flow is fully contacted with the high density atomized water droplets in the air return heat exchanger to complete the heat and moisture exchange between the gas and water. After the exchange, the return air of the mine is discharged to the atmosphere through the baffle plate, and the spray water enters the sink and then is transported to the heat pump unit. The System diagram [11] is shown in Figure 1.
Table 1. Heating load.

\begin{tabular}{llll}
\hline & Winter & $\begin{array}{l}\text { Transition } \\
\text { season }\end{array}$ & Summer \\
\hline building heating load(kW) & 648 & - & - \\
bathing hot water load(kW) & 195 & 160 & 160 \\
Wellhead anti freezing load(kW) & 1725 & - & - \\
Total & 2568 & 160 & 160 \\
\hline
\end{tabular}

The mine fan is a common power equipment with a large energy consumption. In the working process of the mine fan, some heat energy is converted into the potential energy of compressed air, and the other part of the heat energy discharged into the air in the form of waste heat is wasted. At the same time, in order to ensure the normal operation of the air compressor, it is necessary to consume electric energy to start the cooling fan to reduce the oil temperature of the air compressor. In the process of compressor operation, the heat energy of high temperature oil and gas can be transmitted to 
water in normal temperature through high efficiency heat exchanger. As shown in Figure 2, energy conversion is used to preheat the domestic hot water while reducing the temperature of the compressor oil, so as to realize the waste heat recovery [12].

\section{Engineering Situation}

\subsection{Calculating Total Heat Consumption in Mine Wind Field}

1) Floor building heating area is about $7000 \mathrm{~m}^{2}$, and the temperature requirements of heating indoor is 18-24 degrees;

2) A year about 300 staff members need bathing hot water, and the temperature of bathing hot water is more than 45 degrees.

3) Inlet shaft is antifreeze and heated in winter, the air intake is $2200-2500 \mathrm{~m}^{3} / \mathrm{min}$, and the inlet temperature is more than $2{ }^{\circ} \mathrm{C}$ in winter.

After calculation, the maximum load of building heating is $648 \mathrm{~kW}$, the maximum load of bathing hot water is $150 \mathrm{~kW}$, and the wellhead anti freezing heating load is $1725 \mathrm{~kW}$. Calculating loads is shown in Table 1.

Table 2. Air field waste heat resource statistics.

\begin{tabular}{lll}
\hline & Item project & Number \\
\hline \multirow{2}{*}{ Waste heat of } & Installed capacity $(\mathrm{kW})$ & $160^{* 3}$ \\
pressure fans & Average loading rate $(\%)$ & 75 \\
& Cooling oil temperature $\left({ }^{\circ} \mathrm{C}\right)$ & $65-90$ \\
\multirow{3}{*}{ Mine return air } & Return air volume $(\mathrm{m} 3 / \mathrm{min})$ & $6500-8500$ \\
& Exhaust air temperature $\left({ }^{\circ} \mathrm{C}\right)$ & $15-18$ \\
& Relative humidity of exhaust air $(\%)$ & $60-80$ \\
\hline
\end{tabular}

\subsection{Investigation and Analysis of Waste Heat Resource in Mine}

According to field investigation, the situation of waste heat resource with available value in the mine shaft yard is as follows:

\subsection{Calculation of Residual Heat}

1) Calculation of residual heat of pressure fans

The waste heat of pressure fans was evaluated by:

$$
Q_{y}=N \times n \times \rho \times K
$$

Where $\mathrm{N}$ is the single machine capacity for the fan, $\mathrm{n}$ the operation number, $\rho$ the average loading rate, $\mathrm{K}$ the heat recovery rate.

2) Calculation of residual heat in mine [13]

According to the investigation, air return volume of the coal mine is about $6500-8500 \mathrm{~m}^{3} / \mathrm{min}$, the temperature is $15^{\circ} \mathrm{C}$ and the relative humidity is $60 \%$. After the comprehensive heating device, the design air temperature is $2{ }^{\circ} \mathrm{C}$, and the relative humidity is $95 \%$. The residual heat in mine is evaluated by:

$$
Q_{f}=\frac{L \times \rho \times\left(H_{i}-H_{o}\right)}{60}
$$

Where $L$ is the design of air return volume $\left(6500 \mathrm{~m}^{3} / \mathrm{min}\right), \rho$ the return air density, $H_{i}$ and $H_{o}$ the enthalpy value of return air entering and exiting the comprehensive heat collector.

3) Calculation of total waste heat in mine

The total residual heat of well field in mine is given in Table 3. The total heat of the mine shaft is $2659 \mathrm{~kW}$, and the remaining heat fully meets the demand of the air shaft heating load that is $2568 \mathrm{~kW}$.

Table 3. The total waste heat in min.

\begin{tabular}{llll}
\hline Residual sources & Pressure fan & Mine exhaust air & Total \\
\hline Residual heat $(\mathrm{kW})$ & 214 & 2445 & 2659 \\
\hline
\end{tabular}

\section{The Scheme of Waste Heat Utilization}

According to the situation of the residual heat resources of the pressure fanr, the index of heat can fully meet the heating demand of the bath hot water in this field, such as scale, continuity and stability. So the residual heat of the fan can be used as the heating source of the bath hot water system [14]. The residual heat of the fan is about $214 \mathrm{~kW}$, thus three devices are selected for the waste heat recovery. The average heat recovery is $107 \mathrm{~kW}$, and two devices are in operation and one is spare. The operation number of device is corresponding to the fan, and the device runs in a chain. Besides, the system use a separate outdoor pipe network system.

The main engine of the return air heat pump can choose two sets of SRSL-1210, its heat supply is $1220 \mathrm{~kW}$, and the supply and return water temperature is $50^{\circ} \mathrm{C}$ and $45^{\circ} \mathrm{C}$, respectively. Two main sets run in heating season, and two sets of pipe network systems are installed outside the room, which are connected by the distributor and collector in the engine room, one for building heating, another for the wellhead heat use, other seasons stop operating.

In order to ensure the temperature in the borehole to meet the production requirements, facilitating the operation and management, saving energy, six antifreeze air heating equipment are chosen for air heating design of downcast, whose heating capacity is $303 \mathrm{~kW}$ and air volume is $15000 \mathrm{~m}^{3} / \mathrm{h}$, so the total heating capacity is $1818 \mathrm{~kW}$.

\section{System Investment Estimation}

According to the planning and design of heating system and the selection of main equipment [15], the total investment of the heat recovery heating system for the coal mine field waste heat recovery is about 10.97 million yuan, which is detailed in Table 4.

Table 4. Investment estimation of waste heat supply system.

\begin{tabular}{lll}
\hline Device name & Number & Unit price(thousand yuan) \\
\hline Waste heat recovery unit & 3 & 105 \\
First hot water circulating pump & 2 & 4.6 \\
\hline
\end{tabular}




\begin{tabular}{llll}
\hline Device name & Number & Unit price(thousand yuan) & remarks \\
\hline Secondary hot water circulating pump & 2 & 4.6 & One spare \\
Plate heat exchanger & 2 & 49 \\
Thermal storage tank & 1 & 20 \\
Heat preservation and heating water tank & 1 & 20 \\
Water softener device I & 1 & 8 \\
Constant pressure device with makeup water I & 1 & 10 \\
Compressor condensing unit with return air heat pump & 2 & 600 \\
Return air heating box & 8 & 118. \\
Hot water circulating pump & 2 & 20 & One spare \\
Water softener device II & 1 & 18 \\
Constant pressure device with makeup water II & 1 & 18 \\
Special air heating unit for coal mine & 6 & 90 \\
Conveyance system & & 180 \\
Total & & 5244.4 & \\
\hline
\end{tabular}

\section{Analysis of System Benefit}

\subsection{Energy Consumption Analysis [16]}

1) Annual energy consumption of bathing hot water preparation system

The system has only two pumps to consume electricity all year round, and power consumption of each pump is $1.5 \mathrm{~kW}$, which run for 24 hours a day and 365 days a year, so its annual electricity consumption is as follows:

\section{$1.5 \times 2 \times 365 \times 24=26,300 \mathrm{kWh}$}

2) antifreeze and heating system for building heating and measure wells

In winter, two heat pumps, one hot water circulating pumps and six heating units are operating. The winter heating season is calculated for 24 hours a day and 120 days a year. The power consumption is as follows:

$$
(169 \times 20 \times 4+45+3 \times 6) \times 120 \times 24=57,080 \mathrm{kWh} .
$$

3) The total annual electricity consumption of the waste heat heating system in the mine shaft yard is $597,100 \mathrm{kWh}$.

\subsection{Investment and Operation Cost Analysis}

According to the local average electricity price of 0.68 yuan $/ \mathrm{kWh}$, the annual heating power consumption cost of coal mine ventilation shaft heat recovery system is 406,000 yuan.

2) The operation and management cost of a year

About three people are deployed to operate and manage the waste heat supply system. The average annual salary is calculated by 50,000 yuan, so the management cost is about 150,000 yuan.

3) The annual maintenance cost of the system equipment

The total investment of the system is about 5,244, 400 yuan. According to previous engineering experience, the annual operation and maintenance cost of the system can be calculated by $2 \%$ of total investment: $5,244,400 \mathrm{x}$ $0.02=104,888$ yuan.

4) The total annual operating cost of the waste heat supply system is about 661,000 yuan.

5) If the traditional coal-fired steam boiler is adopted to heating, according to the maximum design heat load calculated before, one steam boilers need to be configured whose vaporization is $6 \mathrm{t} / \mathrm{h}$. The overall distribution load of the boiler house is about $60 \mathrm{~kW}$, the comprehensive thermal efficiency of the coal-fired steam boiler is $50 \%$ annually, and the total annual cost is $1,420,000$ yuan. The calculation is shown in Table 5.

1) Energy cost

Table 5. Analysis of operation cost for coal fired boiler.

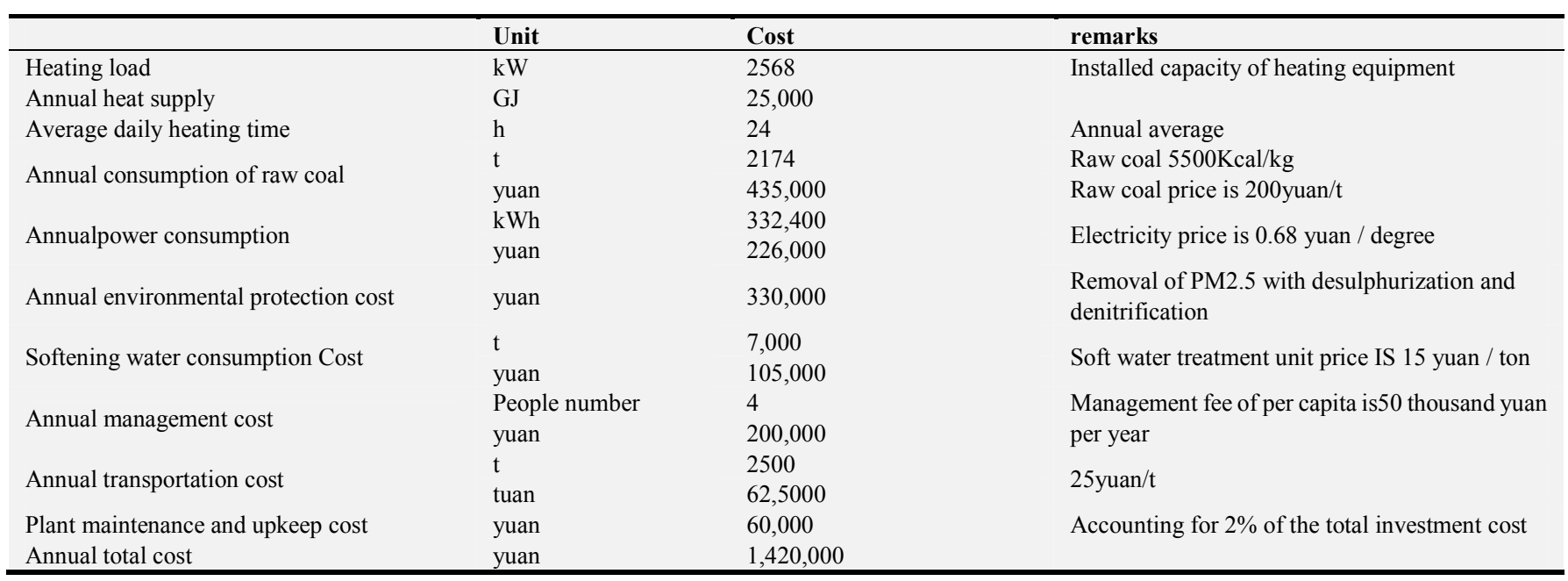




\subsection{Benefit Analysis}

\subsubsection{Economic Benefit}

By calculating, the total investment of the traditional gas boiler and waste heat recovery system are about 3,000,000 yuan and 5,244,400 yuan, respectively. Compared with the coal-fired steam boiler heating system, 759,000 yuan can be saved which is the annual operating cost. The total new investment of this project is about 2,244,400 yuan, and the static investment recovery period is 2.95 years. It can be seen that the project has notable economic benefits.

\subsubsection{Social Benefit}

The annual maximum heating load of the project is $2568 \mathrm{~kW}$, the annual heat consumption of the coal-fired steam boiler system is $25,000 \mathrm{GJ}$, and the waste heat utilization system consumes 791 thousand and 800 degrees. According to China's coal and electricity conversion standard which 1 degree of electricity consume 0.298 kilogram coal, the project is equivalent to the consumption of the standard coal for 236 tons in the whole year. If coal-fired boiler are used for heating and its annual comprehensive thermal efficiency is calculated by $50 \%$, coal fired boiler will consume 1708 tons of standard coal. After the implementation of this project, the burning capacity of standard coal can be reduced about 1472 tons, and its energy saving and emission reduction rate will be as high as $86 \%$. The amount of pollutant reduction is shown in Table 6 and the environmental value of emission reduction is shown in Table 7.

Table 6. Discharge of pollutants.

\begin{tabular}{llllll}
\hline Emission of pollutants & CO2 & SO2 & NOx & PM2.5 flue gas \\
\hline Emission(t) & 3940 & 5.6 & 4.4 & 1617 \\
\hline
\end{tabular}

Table 7. Environmental value of emission reduction.

\begin{tabular}{lllll}
\hline Emission of pollutants & CO2 & SO2 & NOx & PM2.5 flue gas \\
\hline Emission(t) & 3940 & 5.6 & 4.4 & 1617 \\
Environmental value(yuan/t) & 12 & 1400 & 1600 & 163 \\
Total environmental value (yuan) & 47,300 & 7,800 & 7,000 & 220 \\
\hline
\end{tabular}

From the above table, it can be seen that various pollutants can be reduced about 5,800 tons and the environmental benefit is about 331,000 yuan after the implementation of this project.

\section{Conclusion}

Compared with the coal-fired boiler, by using the coal mine waste heat resource utilization system the operating cost can be saved about 971,000 yuan each year. About 1,472 tons of standard coal and 5,800 tons of pollutants are reduced, and the environmental benefits are about 331,000 yuan. This technology possesses significant social, economic and environmental benefits. The utilization system of waste heat resources in mine is used to effectively extract the waste heat of low grade energy and pressures fan in the mine air return, which reduces energy consumption and realizes the low carbon and efficient operation of the system in real sense.

\section{Acknowledgements}

This work was supported by Hefei design and Research Institute of coal industry in China. Special thanks to the chief and technicians for their contribution and support in this work.

\section{References}

[1] Han Lei, "Research status and Prospect of waste heat utilization technology in mine," Application of Energy Technology, no. 10, pp. 36-39, 2013.

[2] Ding Yang, "Application of water source heat pump technology in coal mine cryogenic resource utilization,"Mining
Technology, Vol.11, no. 6, 2011.

[3] Lining Feng, "Study on the amount of waste heat recovery in conventional drying chamber," Forest Engineering, Vol. 28, no. 2, pp. 22-25, 2012.

[4] Fangwen Ning, "Plant diversity in wasteland of Jixi Liu Mao graphite mine," Forest Engineering, Vol. 23, no. 4, pp: 1-4, 2007.

[5] Jinfeng Mao, "Discussion on utilization of mine return air resources," Mining Safety and Environmental Protection, Vol. 42, no. 2, pp. 100-104, 2015.

[6] Deng Bao, "Design of air energy system cooling and waste heat upgrading and utilization system in thermal hazard mine," Refrigeration and Air Conditioning (Sichuan Edition), Vol. 28, no. 3, pp. 302-303, 2014.

[7] Zhenxing Sheng, "Research on heat recovery technology of mine ventilation waste heat," Mining Safety and Environmental Protection, Vol. 36, no. 6, 2009.

[8] Xin Song, "A mine return air waste heat recovery device," China Patent, pp:10-14, 2009.

[9] GuoPingye, "Field experimental study on the cooling effect of mine cooling system acquiring cold source from return air," International Journal of Mining Science and Technology, Vol. 23, no. 3, pp. 453-456, 2013.

[10] Guo Pingye, "Field experiment on coalmine heat disaster governance using cold source from surface water," International Journal of Mining Science and Technology, Vol. 24, no. 6, pp. 865-869, 2014.

[11] Wang Yunfang, "Research on utilization technology of waste heat resources of mine ventilation in Dian Ping mine," Shanxi Coking Coal Science and Technology, no. 9, pp. 19, 2014. 
[12] Wang Yan, "Research and application of comprehensive utilization of thermal energy recovery for mine fans," Energy Technology and Management, Vol. 39, no. 4, pp. 139-130, 2014.

[13] Junhui Liu, "Application of wind source heat pump system in Dong Peng coal mine," Hebei Coal, no. 3, pp. 66-68, 2012.

[14] Xuedong Guo, "Technical practice of waste heat recovery device for mine pressure fans," Field of Science and Technology, no. 28, pp. 401-403, 2012.

[15] Zui liang Ma, "Design and application of ground source heat pump system," Beijing: Machinery Industry Press, 2007.

[16] Dongdong Zhu, "Energy saving analysis of the backdraft air source heat pump system in Shuguang coal mine," China High and New Technology Enterprise, no. 24, pp. 75-77, 2013. 